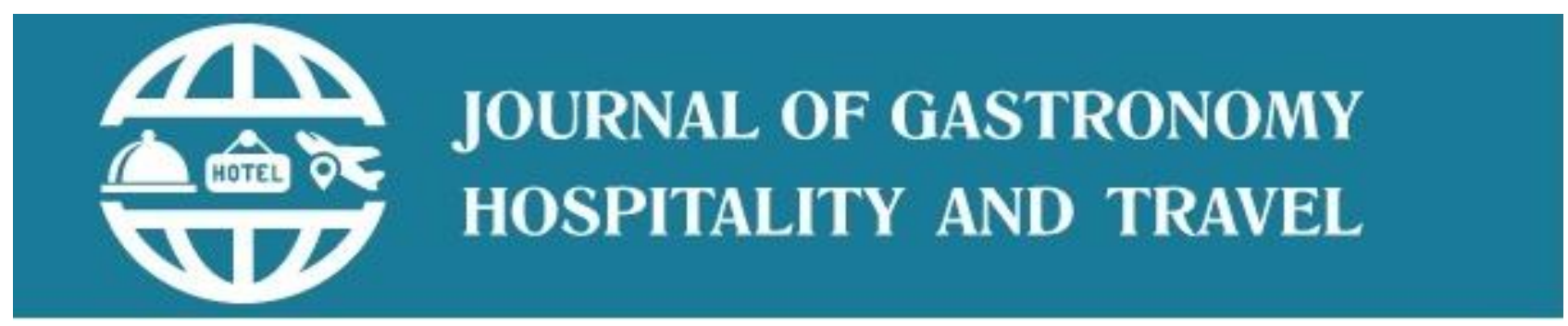

\title{
Research Article \\ EVALUATION OF THE LEARNING OUTCOMES STATEMENTS OF THE ENGLISH COURSES AT TOURISM FACULTIES IN TURKEY THROUGH THEIR WEB-SITES
}

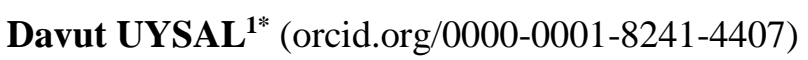 \\ *Ph.D., Anadolu University, School of Foreign Languages, Eskişehir, Turkey
}

\begin{abstract}
Learning outcomes statements in English courses, as they are true for all other courses, are central to each course. Without having appropriately stated learning outcomes, it is almost impossible to set goals, objectives for the course and to prepare relevant assessment tools for English language practitioners, and thus to teach the target language. Considering that foreign language teaching is a major problem at tourism faculties in Turkey, that tourism students often fail to use the target foreign language, this study intended to examine the course contents of the English courses, specifically learning outcomes considering that they have a guiding role in language teaching. For this purpose, 10 tourism faculties were chosen randomly and their websites were visited by the researcher. The English courses given in the first term was chosen to ensure standardisation in data collection and sampling. It was found with this study that $50 \%$ per cent of the visited faculties had no data available regarding the content of the English courses on their web sites. It was also found that the learning outcomes statements of the accessed 5 faculties do not meet the criteria set to state appropriate learning outcomes statements. Relevant conclusions were drawn for complete program development at tourism faculties for effective English language teaching and for the major causes of the failure in teaching English as a foreign language at tourism faculties.
\end{abstract}

Keywords: Learning Outcomes, Tourism Faculties, English Course

\section{Introduction}

The term "learning outcome" is defined as a formal statement expressing what students are expected to learn in a certain course. Learning outcome statements need to refer to specific knowledge, practical skills, areas of professional development, attitudes, higher-order thinking skills etc. that course practitioners expect learners to develop, learn or master during a certain course (Suskie, 2004). Learning outcomes statements are also defined as the statements expressing what learners are expected to know, understand and/or be able to demonstrate after completing the process of teaching (Users' Guide ECTS, 2005, Stephen, 2004). Learning outcomes function as a navigation tool such as GPS which is commonly used when travelling. When a certain destination is set on the GPS, the device guides its user throughout the journey and takes him/her to the target destination. When a traveller takes a wrong route accidentally, it is the responsibility of the GPS to warn the traveller and create a new route and then take the traveller to the target destination. Similar to the case

\footnotetext{
${ }^{1}$ To cite this document: Uysal, D. (2019). Evaluation of The Learning Outcomes Statements of The English Courses at Tourism Faculties in Turkey through Their Web-Sites, Journal of Gastronomy Hospitality and Travel, 2(2), 171-181. DOI: 10.33083/joghat.2019.25
} 
of GPS, learning outcomes help teachers to guide their students to the intended learning and gains in their courses. They also inform students about the path to be followed and tell students what they will have learned at the end of the process (Mahajan and Singh, 2017).

In summary, learning outcome statements describe:

- what teachers/institutions expect students to know at the end of a course, and

- what teachers/institutions expect students to be able to do at the end of a course.

Appropriately stated learning outcomes are supposed to have three major characteristics;

- they should specify an action by the learners that is observable,

- they should specify an action by the learners that is measurable, and

- they should specify an action that is done by the learners (rather than the teachers)

Effectively and appropriately developed and stated learning outcomes statements are supposed to have all of these characteristics. Only with this way, it will be possible for a course to be effective and to be assessed (Suskie, 2004). This study aims to investigate the web sites of tourism faculties in Turkey, specifically the learning outcomes of the Vocational and General English courses at tourism faculties. In other words, this study was designed to make a content analysis of the English courses to find out to what extent the learning outcomes of English courses at tourism faculties meet the criteria which were adapted from WACSLO (2017) and summed up as follows:

- Limited to 5 - 10 statements (Criterion 1)

- Focus on overarching or general knowledge and/or skills (Criterion 2)

- Focus on knowledge and skills that are central to the course topic (Criterion 3)

- Student-centred rather than being faculty-centred (Criterion 4)

- Focus on the learning that results from the course rather than describing activities (Criterion 5)

- Incorporate or reflect the institutional and departmental missions (Criterion 6)

- Incorporate various ways for students to show success (outlining, describing, modelling, depicting, etc.) rather than using a single statement (Criterion 7)

- Observable (Criterion 8)

- Measurable (Criterion 9)

\section{Literature Review}

\subsection{Writing Effective Learning Outcomes Statements}

When stating learning outcomes, it is important to use the verbs describing exactly what the learner will be able to do when they complete the course taken. Some of the words are considered to be unclear when used in learning outcomes statements such as "know", "be aware of", "appreciate", "learn", "understand", "comprehend", "become familiar with" because these words express indefiniteness and they can cause more than one interpretation in the minds. They are also difficult to observe and measure (American Association of Law Libraries, 2005). Because of these reasons, it is always better to avoid using such words expressing indefiniteness in stating learning outcomes for a certain course.

The following learning outcomes cannot be claimed to be good examples of learning outcomes;

By the end of the course, students will

- understand the basic knowledge about the history of the human being.

- appreciate some example of folk music from other cultures. 
Both of these outcomes are difficult to assess by the course practitioner because you cannot observe if someone understands something or not. You also cannot know if someone appreciates the folk music of other cultures or not, and the practitioner also cannot design a test to do that. The learning outcomes statements which have been criticized above could be restated more effectively by changing the verbs as in the following examples;

By the end of the course, students will be able to

- identify and describe the major knowledge about the history of the human being.

- identify the characteristics of folk music types from other cultures.

These learning outcomes have been stated with the use of an action verb "identify", which is both observable and measurable because course practitioners can design a test or a tool to test if students identified or described. They also express an action which will be performed by the learners as the centre of teaching-learning processes rather than teachers or someone else.

\subsection{Incorporating Critical Thinking Skills into Learning Outcomes Statements}

Many teachers or course practitioners tend to incorporate words reflecting critical thinking into the learning outcomes of their courses. Bloom (1956) developed and suggested a taxonomy to outline various thinking skills used in processing various types of information and situations. Some of these are basic cognitive skills; however, others are difficult skills. Such skills are also mentioned as critical thinking skills. Bloom suggested the following taxonomy of thinking skills, all of which cannot be reflected in the learning outcomes statements. The taxonomy suggested by Bloom was adapted by Anderson and Krathwohl (2001) under the heading of different levels of thinking skills as follows;

1. Remember - recalling relevant terminology, specific facts, or different procedures related to information and/or course topics. Student, at this level of the taxonomy, can remember something, but they may not understand it fully.

2. Understand - the ability to grasp the meaning of the presented information such as facts, definitions, concepts, etc.

3. Apply - to be able to use the learned information in various situations or problem-solving.

4. Analyse - the ability to break information down into its components. This level is also closely related to the process of examining information to conclude the cause and effect, interpreting motives, making inferences, or finding evidence to support statements/arguments.

5. Evaluate - to be able to judge the value of information and/or sources of information filtering it in line with their values or opinions.

6. Create - the ability to creatively or uniquely apply prior knowledge and/or skills to produce new and original thoughts, ideas, processes, etc. Only at this level, students are involved in creating their thoughts and ideas based on what has been learned.

Learning outcomes are important indicators of achievement in an academic course/program. Learning outcomes give a clear idea about what could be achieved when learners join a course/program. No matter what kind of courses they are, all courses should be listed and written before the course starts to make sure that the course has been designed perfectly. Based on the stated learning outcomes, teaching environment, classroom activities and assessment tools have to be designed appropriately to conduct and complete the course successfully (Mahajan and Singh, 2017).

\subsection{Benefits of Learning Outcomes in Teaching}

With the help of clearly stated learning outcomes, learners could understand what they are supposed to learn through the course that they are about to take. Learning outcomes also help learners to choose an appropriate course to their learning. Well-stated learning outcomes also help learners and teachers avoid wasting their valuable time, and reduce potential stress on learners. Learning outcomes point out what exactly and more importantly learners need to know to gain maximum learning from a course. When the stated learning outcomes are achieved by learners, they can have 
the chance to demonstrate that they have reached the target of the course and get the maximum benefit from the taken course (Mahajan and Singh, 2017).

Well-stated learning outcomes also provide some other benefits for the course practitioners. Learning outcomes help course practitioners to easily plan their courses. Learning outcomes also help course practitioners have a clear idea of what and how much to teach and plan further teaching accordingly. With learning outcomes, course practitioners can design their classroom materials more effectively to provide maximum learning for learners. Learning outcomes also provide chances for course practitioners to use appropriate strategies to use in their teaching. Learning outcomes also help course practitioners avoid extra teaching by saving their time (Mahajan and Singh, 2017).

Learning outcomes also make the assessment and the planning of assessment clear and easy as well as the evaluation of courses. Learning outcomes make midway correction possible and help students study in their way and come to the class prepared. Learning outcomes also facilitate measuring and helps to measure methods effectively function. Learning outcomes help accreditation agencies to assess whether the course/programme has met the mission and goals of the institution where the teaching is performed as well as deciding if the desired objectives of the institution have been met or not. Learning outcomes function as a kind of evidence such as rubric, charts and graphs about the summative learning goals. (Mahajan and Singh, 2017).

\subsection{List of Action Words Related to Critical Thinking Skills}

There are some action words which should be used to state learning outcomes related to critical thinking skills in a certain course. These action words are categorized based on the different levels of higher-order thinking skills suggested by Anderson and Krathwohl's (2001) revising the version created in Bloom's (1956) taxonomy. They could be summarized as seen in Table 1.

Table 1: Action words categorized based on the different levels of higher-order thinking skills

\begin{tabular}{|c|c|c|c|c|c|}
\hline REMEMBER & UNDERSTAND & APPLY & ANALYZE & EVALUATE & CREATE \\
\hline Define Describe & Associate & Add & Analyse & Assess & Categorize \\
\hline Draw & Compute & Apply & Arrange & Compare & Combine \\
\hline Identify & Convert & Calculate & Combine & Conclude & Compose \\
\hline Label & Defend & Change & Design & Contrast & Create \\
\hline List & Discuss & Classify & Develop & Criticize & Drive \\
\hline Match & Distinguish & Complete & Diagram & Determine & Design \\
\hline Name & Estimate & Compute & Differentiate & Grade & Devise \\
\hline Outline & Explain & Demonstrate & Discriminate & Interpret & Explain \\
\hline Point & Extend & Discover & Illustrate & Judge & Generate \\
\hline Read & Generalize & Divide & Infer & Justify & Group \\
\hline Recall & Infer & Examine & Outline & Measure & Integrate \\
\hline Recognize & Paraphrase & Interpolate & Point out & Rank & Modify \\
\hline Record Repeat & Predict & Modify & Relate & Rate & Order \\
\hline Reproduce & Rewrite & Operate & Select & Support & Organize \\
\hline Select & Summarize & Prepare & Separate & Test & Plan \\
\hline State & & Produce & Utilize & & Prescribe \\
\hline Write & & Show & & & Propose \\
\hline & & Solve & & & Rearrange \\
\hline & & Translate & & & Reconstruct \\
\hline & & Use & & & Related \\
\hline & & & & & Reorganize \\
\hline & & & & & Revise \\
\hline & & & & & Rewrite \\
\hline & & & & & Summarize \\
\hline & & & & & Transform \\
\hline & & & & & Specify \\
\hline
\end{tabular}

Source: Adapted from Anderson and Krathwohl (2001)

There are some basic tips to be used for developing course-level learning outcomes statement and they could be stated as follows ( Adapted from WACSLO, 2017): 
- The course-level learning outcomes should be limited to $5-10$ statements for the entire course. If there is a need for detailed outcomes, units, assignments and chapters could be used for that purpose.

- Overarching or general knowledge and/or skills should be focused rather than small or trivial details.

- The knowledge and skills that are the main focus of the course topic and/or discipline should be given priority.

- Statements should be student-centred rather than faculty-centred (e.g., "upon completion of this course students will be able to list the names of the 50 states in English" versus "one objective of this course is to teach the names of the 50 states").

- The learning that results from the course should be focused rather than describing activities or lessons in the course.

- Statements need to incorporate or reflect the institutional and departmental missions already set.

- Statements need to incorporate various ways for students to show their success (outlining, describing, modelling, etc.) rather than being a single statement such as "at the end of the course, students will know " as the stem for each outcome statement of the course.

The following learning outcomes could be offered as good examples for an ideal English course.

Name of the Course: Introduction to Tourism English

At the end of the course, students will be able to:

- Identify the adjectives used to describe current positions in the tourism sector

- Explain how a product/service works to a client upon request

- Define the basic rules of the organisation where they work for clients

- Compare and contrast the different services offered in their work environment

- Evaluate and classify various services/products upon request

- Summarize how technology could be used to facilitate check-in procedures

\subsection{Assessment and Role of Learning Outcomes in Assessment in Education}

Assessment is about the systematic collection, review, and use of evidence or information about what students have learned in a course. With the help of assessment, course practitioners can understand how well their students understand course topics. Assessment aims to detect students' understanding to decide what areas of the course need to be re-visited to help students learn the subject better (Palomba and Banta, 1999)

In other words, assessment is a way of examining what the students taking the course are learning and how well they are learning the outcomes of the course. This process could also be used for giving feedback about their learning and also offering them more opportunities and strategies to increase their learning (Palomba and Banta,1999)

Assessment is considered to be very important in teaching processes because, with the help of assessment, practitioners could find out the level of skills or knowledge of their students (Taras, 2005). Similarly, Wojtczak, (2002) claims that assessment helps practitioners evaluate the strengths and weakness of their students and to increase their motivation to learning and the course (Taras, 2005; Stiggins, 1992). Assessment is done to help course practitioners decide how many of their students have achieved the learning objectives of the courses, who are suffering from difficulties in their learning and which of the techniques are useful in teaching the course. With the help of assessment, course practitioners can also decide whether to continue or stop teaching the foreign language (Maki, 2004). To be able to achieve all of these, an ideal course needs to have appropriate 
learning outcomes statements. Without learning outcomes statement, it will not be possible for course practitioners to obtain the benefit provided by the assessment tools in a course.

\section{Method}

As this study intended to investigate the learning outcomes of English courses at tourism faculties in Turkey, 10 tourism faculties from 10 different state universities were randomly chosen through simple random sampling method. The web sites of the chosen faculties were visited in December 2018. During the visits, the researcher chose to visit the English courses given at the department of "Tourism management" in the $1^{\text {st }}$ term from each tourism faculty for standardization purpose in sampling and the accessed learning outcomes from the visited courses were evaluated in line with the 9 criteria given above. One English course from each visited faculty was taken as a sample in the study. To ensure the privacy of the chosen faculties, each faculty was coded with a letter between $\mathrm{A}$ and $\mathrm{E}$. The accessed learning outcomes from the visited websites were transferred to a table and given a code. Then each learning outcome was translated into English by the researcher who is also an English language expert in his field. What was important with the translation of the obtained learning outcomes into English was to leave any mistake or error related to function and form as it is in the translation process.

\section{Results}

The web sites of 10 faculties from 10 state universities were visited on the stated dates and only five of them were found to have had a list of learning outcomes for the visited English course. The rest of the visited universities were found to have no detail regarding course content, organisational/departmental mission and objectives, which is equal to almost $50 \%$ of the visited faculties. The learning outcomes of the visited English courses are given in tables below and then they are evaluated based on the criteria set in the study.

\subsection{List of Learning Outcomes of Faculty A}

\begin{tabular}{|l|}
\hline LO1. Learning English words \\
\hline LO2. Learning the basic terms of the English language \\
\hline LO3. Teaching English as a communication system \\
\hline LO4. Helping students gain necessary language skills \\
\hline LO5. Understanding the texts heard or listened \\
\hline LO6. Introducing himself/herself and asking personal questions to others \\
\hline LO7. Students understand the basic form of verbs \\
\hline
\end{tabular}

When the Faculty A was evaluated according to the criteria set in the study, the number of learning outcomes seems to be ideal in number as it has stated 7 learning outcomes for the course (Criterion 1). When the outcomes of the chosen English course were evaluated with regards to Criterion 2, it is seen that the stated outcomes of the course are too general and more than achievable. When they were evaluated based on Criterion 3, it is seen that the stated outcomes seem to be far away from the course content as they were not stated as specific statements. When they were evaluated based on Criterion 4, some of the statements seem to be learner-centred (e.g. 1, 2, 5, 6 and 7 ), the rest of the statements seem to have been written in a teacher-centred way. However, all learning outcomes are supposed to be learner-centred rather than being teacher-centred as each course is expected to learning. When the learning outcomes were evaluated based on Criterion 5 , they were found to have focused on the learning that does not or cannot result from what is done in the classroom as almost all of them seem to be too general to achieve in one-term English course. The stated outcomes could not be evaluated based on Criterion 6 because no relevant knowledge could be obtained by the researcher when the relevant university's web site was visited. The stated outcomes do not incorporate various ways for the learners to gain achievement (Criterion 7). The obtained 
learning outcomes of the visited course seem not to have been stated as observable and measurable statements (Criterion 8, 9). For example, the use of "understand" is very common, but it is not possible for course practitioners to assess if students have understood or not through an assessment tool.

\subsection{List of Learning Outcomes (LOs) of Faculty B}

LO1. To be at the level to be able to understand advanced level speaking, listening skills as well as understanding TV news programs and following the agenda

LO2. To be able to write detailed and clear passages on various topics

LO3. Communicating with those speaking in their mother tongue and being involved in discussions actively

LO4. Reading and understanding the articles and reports about daily life

LO5. Determining the idioms often used, and often confusing and to be able to use them effectively

LO6. To be more proficient to write comprehensive and longer logical sentences by improving their speaking and writing skills

The learning outcomes statements of Faculty B were evaluated based on the criteria set in the study. It was found that the number of learning outcomes statements seem to be appropriate in quantity as stated in Criterion 1. The stated outcomes express too general course aims as in LO 1 (Criterion 2). Considering what is stated in the obtained learning outcomes cannot be achieved in one English course, it should be stated that Criterion 3 was violated. The statements aim students' learning the skills that cannot be central to one English course given in one academic term. When the statements were evaluated based on Criterion 4, it is seen that they all seem to have been stated in a way to be learner-centred as they all focus on students' learning rather than teachers' teaching. When the learning outcomes statements were evaluated based on Criterion 5, it is seen that what is aimed and stated in these statements cannot be the results from one English course. The researcher couldn't evaluate the learning outcomes statements based on criterion 5 as the researcher could not find the institutional and departmental missions on the visited web sites on the visit. Some of the learning outcomes statements seem to be measurable and observable (eg. 2); however, we have to state that they are not stated in full sentence as supposed to be.

\subsection{List of Learning Outcomes of Faculty C}

LO1. Students can introduce themselves

LO2. Students can ask for someone's job and can tell what the third body's jobs are

LO3. Students can ask someone's age and phone number.

LO4. Students can recognize plural and singular nouns and can refer to these nouns with pronouns

LO5. Students can ask for the quantity of the objects and can respond to such questions

LO6. Students can ask for the time of the day and can respond such questions giving details such as time, day, month and season

LO7. Students can recognize prepositions of time and tell about the time using the prepositions of time

LO8. Students can recognize possessive suffixes

LO9. Students can recognize prepositions of place. Students can combine two separate sentences using an appropriate conjunction.

LO10. Students can recognize the sentences in Simple Present tense and can produce sentences in Simple Present Tense.

LO11. Students can recognize adverbs of frequency and use them appropriately 
When the learning outcomes statements of Faculty $\mathrm{C}$ were evaluated based on the criteria set in the study, it is seen that they were stated in full sentences as they were supposed to be. Whereas an ideal number for stating learning outcomes is between 5 and 10, as more than 10 could be difficult to achieve in one course, this course has 11 learning outcomes statements, which seem to signal the violation of Criterion 1. When the statements were evaluated based on Criterion 2, it is seen that they were stated in a form to help the course focus on overarching or general knowledge and/or skills (Criterion 2) as well as focusing on the knowledge and skills central to the course topic as what was stated in the outcomes statements are achievable in one single course. (Criterion 3). All of the statements also seem to have been stated in a learner-centred way (Criterion 4). As what is stated in the outcomes statements could be achieved in one course in an academic term, it is possible to post similar comments about the learning outcomes of the visited course (Criterion 5). When the learning outcomes were evaluated based on Criterion 6 , it is seen that they incorporate or reflect the institutional and departmental missions (Criterion 6) as it was possible for the researcher to access the institutional and departmental missions of the visited faculty. However, the obtained statements were evaluated based on Criterion 7, it was found that they do not incorporate various ways for students to show success (outlining, describing, modelling, depicting, etc.) (Criterion 7). The evaluated learning outcomes were also found to have been stated in an observable and measurable way (Criterion 8,9). It is also noteworthy here that some of the stated learning outcomes need to be divided into two different sentences.

\subsection{List of Learning Outcomes of Faculty D}

Comprehensive repetition of the topics covered in the course such as past tense, simple present tense, present continuous tense and modal verbs with the help of listening, reading, speaking and writing exercises, repetition of present perfect tense, if clauses (If 1 and If 2), basic adjective clauses, noun clauses and basic passive structures

When the learning outcomes of the Faculty D were evaluated based on the criteria set in the study, it is seen that so-called learning outcomes (as they were stated under the name of "learning outcomes") were not stated in full and separate sentences, which made it impossible for the researcher to evaluate them based on Criterion 1. They were all stated in phrases. The phrases are too general and they seem to be the continuation of another course rather than an independent course (Criterion 2). Therefore, it cannot be stated that they are not central to the course or not (Criterion 3). Therefore, Criterion 4, 5, 6, 7, 8, and 9 were assumed to have been violated in this visited course.

\subsection{List of Learning Outcomes of Faculty $E$}

LO1. Developing positive attitudes towards the target language

LO2. Students gain the skills necessary for their academic life and communication purpose in the target language.

LO3. Students gain intermediate-level grammar knowledge.

LO4. Students explain the intermediate level texts which are read aloud in the target language.

LO5. Reaching the intermediate writing proficiency level in the target language. In this direction, they write a paragraph first and then an essay.

LO6. Students reach intermediate level listening comprehension proficiency

LO7. Students can express themselves verbally

LO8. Students can communicate with those speaking the target language as their mother tongue and as a foreign language.

The learning outcomes statements of the Faculty E were evaluated. It was found that the number of learning outcomes statements met the ideal limit as 8 learning outcomes statements have 
been accessed with the visited English course (Criterion 1). When they were evaluated based on Criterion 2, it was seen that they were all too general statements (eg, developing positive attitudes, gaining the skills necessary for academic life). Therefore, they cannot be central to one English course, which means a violation of Criterion 3. The evaluated learning outcomes seem to have been stated in a learner-centred way (eg, students gain, students explain"; however, they express a target which cannot be achieved by the learners by taking this course (eg. reaching intermediate writing skills) (Criterion 4). These statements cannot be the results of one English course as they express too general aims which cannot be achieved in one English course (Criterion 5). As institutional and departmental missions could not be obtained on the visited website of the relevant faculty, the researcher couldn't evaluate the statements based on Criterion 6. The evaluated learning outcomes statements also do not incorporate various ways for learners to show achievement, which means a violation of Criterion 7. The evaluated learning outcomes are also not measurable and observable (Criterion 8 and 9), which make their assessment with assessment tools.

\section{Discussion and Conclusion}

As seen from the evaluation of the learning outcomes statements of the visited English courses, tourism faculties have serious problems with their English programs. This is evident from the fact that 5 out of 10 tourism faculties visited within the scope of the study were found not to have lists of learning outcomes for their English courses and even the organisational and departmental mission statements. Those which were found to have lists of learning outcomes for the English courses given at the faculties, but the obtained learning outcomes statements had serious problems with regards to form and function, all of which is a signal for the fact, as suggested by Uysal and Seçilmiş (2019) who conducted a detailed needs analysis for tourism faculties and proposed a model for the effective teaching of English at tourism faculties, that tourism faculties need to undergo a curriculum renewal for better English teaching. This can also be used to conclude that English language instructors at tourism faculties are unaware of the needs of their students for the use of English for communication purpose (Uysal \& Seçilmiş, 2019) and thus tourism students are also unaware of their needs.

Learning outcomes have guiding roles in all courses and the stated learning outcomes statements guide the whole teaching process and control lecturers as well as helping them and learners reach the set learning goals of the courses. They also have critical roles in the assessment process because the assessment is a way of collecting feedback from students and learning outcomes also ensure that what is taught in the course is assessed in exams, which make assessment tools effective in measuring students' learning. Under the light of the findings of this study, it is almost impossible to claim that what is taught is measured in the exams at tourism faculties as the accessed learning outcomes are different from what is done in the classroom. As the visited English courses were found, in general, not to have appropriately stated learning outcomes, it could also be concluded that the course objectives, course materials and assessment tools are not effective in promoting the aimed learning at these faculties and that students are not given enough chance to get appropriate feedback about their learning from the assessment tools, considering that assessment tools are not developed appropriately. Another conclusion that we can draw is that we cannot talk about effective coordination among English courses as coordination is one of the most basic characteristics of English courses from the other courses. Because, in English programs, each course builds learning on another, and prepares students for learning in their future courses, which is ensured with the learning outcomes statements appropriately stated and coordinated for each course. The findings of this study suggest that there is not any coordination among the courses even within a faculty whereas each English course in an English teaching program builds learning for future English courses.

It could be claimed that the courses examined within the scope of this study might have had appropriately stated learning outcomes and they might not have been updated on the visited websites. We can claim, as a counter-argument, that no organisation would keep inappropriately stated learning 
outcomes on their websites which are the most exposed face of these institutions, whereas they have appropriately stated learning outcomes for their courses.

The findings of this study could also be used to conclude that assessment tools used in English courses at tourism faculties are not developed in a way to promote expected learning. Because learning outcomes statements of an English course have guiding roles in developing appropriate assessment tools to ensure that what is taught is measured through appropriately developed assessment tools. Therefore, it cannot be claimed that assessment is done effectively in the courses where course aims and objectives are not formed appropriately. The findings could also be used to suggest that tourism faculty students lack the opportunity to learn what they are going to learn in an English course which they are about to take at the beginning of the term as the web sites say different things from what teachers do in their courses. In brief, as Mahajan \& Singh (2017) claimed, no one can get a clear idea about what could be achieved with the courses/program at tourism faculties which are the core of this study. As it is true for all kind of courses, all courses should be listed and written before the course starts and learners should be ensured that courses have been designed perfectly. Based on the stated learning outcomes, teaching environment, classroom activities and assessment tools have to be designed appropriately to conduct and complete the course successfully (Mahajan and Singh, 2017). Only with this way, it will be possible to improve the quality of foreign language teaching at tourism faculties in Turkey. Under current conditions at tourism faculties, nobody can be sure if the mission and goals of the institution have been met as well as deciding if the desired objectives of the institution have been reached.

\section{REFERENCES}

American Association of Law Libraries (2005). Writing learning outcomes. Available at http://www.aallnet.org/prodev/outcomes.asp. Access Date: 22 March 2018

Anderson, L.W., \& Krathwohl, D.R. (2001). A taxonomy of learning, teaching, and assessment: A revision of Bloom's taxonomy of educational objectives. New York: Longman.

Bloom, B.S., (1956) Taxonomy of educational objectives: The classification of educational goals: Handbook I, cognitive domain. Longmans, Green: New York, NY.

Users' Guide, ECTS., (2005). Brussels: Directorate-General for Education and Culture.

Mahajan, M., \& Singh, M. K. S. (2017). Importance and Benefits of Learning Outcomes. IOSR Journal of Humanities and Social Science. 22(3), 65-67. p-ISSN: 2279-0845.

Maki, P. L. (2004). Assessing for learning: Building a sustainable commitment across the institution. Stylus: Sterling, VA.

Palomba, C. A. \& Banta, T.W. Eds. (2001). Assessing student competence in accredited disciplines: Pioneering approaches to assessment in higher education. Stylus: Sterling, VA.

Stephen, A. (2004). Using learning outcomes-A consideration of the nature, role, application and implications for European education of employing learning outcomes at the local, national and international levels. University of Westminster, Edinburgh.

Stiggins, R. J. (2002). Assessment Crisis: The Absence of Assessment for Learning. Phi-Delta Kappan, 83(10), 758-765. https://doi.org/10.1177/003172170208301010

Suskie, L. (2004). Assessing student learning: A common sense guide. Bolton, MA: Anker Publishing. 
Taras, M. (2005). Assessment- Summative and Formative-Some Theoretical Reflections. British Journal of Educational Studies, 53(4), 466-478. https://doi.org/10.1111/j.1467$\underline{8527.2005 .00307 . x}$

Uysal, D., \& Seçilmiş, C. (2019). Turizm Fakültesi Öğrencilerinin İngilizce İletişim Becerilerinin Geliştirilmesine Yönelik Gereksinim Çözümlemesine Dayalı Bir Program Önerisi. MANAS Sosyal Araştırmalar Dergisi, 8(4), 3808-3835.

WACSLO, (2017). Writing and Assessing Course-Level Student Learning Outcomes, Office of Planning and Assessment. Texas Tech University. Available at: https://www.academia.edu/36368144/Writing_and_Assessing_CourseLevel_Student_Learning_Outcomes_Office_of_Planning_and_Assessment

Wojtczak, A. (2002). Medical Education Terminology. Medical Teacher, 24(4), 357-357. https://doi.org/10.1080/01421590220145699 